\title{
O DESENVOLVIMENTO COMO PRESSUPOSTO NA "NATUREZA HUMANA": das abordagens didático-metodológicas sobre desenvolvimento à abordagem territorial do desenvolvimento rural
}

\section{DEVELOPMENT AS PRESUPPOSITION IN "HUMAN NATURE": from didactic-methodological approaches on development to the territorial approach of rural development}

Paulo Cesar Souza

Universidade Estadual Paulista - FCT/UNESP, Campus de Presidente Prudente paulinhogeo@hotmail.com

\begin{abstract}
Resumo
Desenvolvimento tem sido entendido, ao longo das últimas décadas, como sinônimo de crescimento econômico, conceito aprimorado junto às economias ricas da OCDE, para designar industrialização, mecanização, tecnologia e aporte financeiro nessas áreas. Entretanto, após os anos 1960, esse conceito tem passado por novas abordagens metodológicas ligadas às mudanças substanciais nos meios de vida social e aos problemas abrangentes na sociedade global. Surgiram, então, as dimensões do desenvolvimento social, do desenvolvimento humano e do ambiental, todas carregadas de sentidos mais integrados sobre o tema. Nessa perspectiva, o texto procura mostrar a importância dessas novas dimensões vinculadas à abordagem territorial do desenvolvimento, partindo-se do pressuposto do meio rural, objetivando essa nova dinâmica desenvolvimentista conceituada no conjunto dos recursos naturais e humanos presentes no território, podendo ser ordenados e aproveitados no contexto social, via promoção da vida, inclusão e dignidade das populações pobres e futuras gerações.
\end{abstract}

Palavras-chave: Desenvolvimento. Recursos naturais. Território. Meio rural. Populações pobres.

\begin{abstract}
Development has been understood over the last decades as a synonym for economic growth, an improved concept with the rich economies of the OECD to designate industrialization, mechanization, technology and financial support in these areas. However, after the 1960s, this concept has gone through new methodological approaches linked to substantial changes in social livelihoods and the broad problems in global society. They then emerged to the dimensions of social development, human development and the environment, all loaded with more integrated senses on the subject. In this perspective, the text seeks to show the importance of these new dimensions linked to the territorial approach of development, starting from the rural environment assumption, aiming at this new developmental dynamics conceptualized in the set of natural and human resources present in the territory, being able to be ordered and used in the social context, saw the promotion of life, inclusion and dignity of the poor and future generations.
\end{abstract}

Key-words: Development. Natural resources. Territory. Rural áreas. Poor populations. 
O desenvolvimento como pressuposto na "natureza humana": das abordagens didático-metodológicas sobre desenvolvimento à abordagem territorial do desenvolvimento rural

\section{Introdução}

Este texto compreende um resumo das análises do arcabouço teórico da Tese de Doutorado Políticas Públicas e Desenvolvimento Rural na Região de Presidente Prudente, defendida junto ao Programa de Pós-Graduação em Geografia da Faculdade de Ciência e Tecnologia de Presidente Prudente, da Universidade Estadual Paulista (PPGGFCT/UNESP), em julho de 2012. A pesquisa, concluída em 2012, tinha como objetivo identificar as possibilidades do desenvolvimento rural em município de pequeno porte do Oeste Paulista, unidades territoriais com economias fortemente relacionadas ao meio rural e à produção agropecuária. Nesse contexto, procurou-se estabelecer a tese de que as regiões pobres podem ser vocacionadas para o desenvolvimento, desde que estejam inseridas dentro de uma rede de articulações políticas, sociais, econômicas e espaciais, partindo-se da hipótese de que políticas públicas desenvolvimentistas são ferramentas para alavancar o desenvolvimento e proporcionar, através da interação de agentes sociais locais, do Estado (em seus níveis hierárquicos) e do capital privado, o que se entende, de fato, como "abordagem territorial do desenvolvimento".

O texto está subdividido em dois itens. O primeiro identifica um conjunto de abordagens metodológicas sobre o conceito de desenvolvimento, na modernidade, dentro das correntes da história social, ao culminar na percepção do desenvolvimento sustentável, na passagem para o século XXI. O segundo explana análises conceituais na perspectiva desenvolvimentista, por meio da abordagem territorial do desenvolvimento rural, levando-se em conta a capacidade do conjunto de elementos naturais e humanos dos territórios, enviesados pela execução de políticas públicas. Por fim, procura-se evidenciar a importância de entender o processo atual do desenvolvimento como prerrogativa para inclusão, condições de vida e dignidade das áreas pobres e suas futuras gerações.

\section{Abordagens didático-metodológicas sobre desenvolvimento e desenvolvimento sustentável}

O termo desenvolvimento, largamente empregado nas economias capitalistas, pósRevolução Industrial - a XVIII -, tem recebido, ao longo desse período, várias conotações. Segundo Favareto (2007, p. 37), a grande interrogação que paira sobre a ideia 
de desenvolvimento “[...] é saber se é possível decantar o que há de científico e o que há de normativo, de ideológico, de meramente discursivo por detrás dela."

A questão do desenvolvimento já aparece com o evolucionismo e o naturalismo do século XIX - com Darwin, em “A Origem das Espécies”, quando as relações sociedade e natureza foram enfocadas com base no desenvolvimento da espécie humana, sua adaptação e controle dos meios naturais e na construção das organizações sociais e econômicas (ENGELS, 1891). Ideias de desenvolvimento e evolução surgem atreladas às interpretações racionais do mundo e da vida, na Grécia Antiga. A gênese do desenvolvimento, nesse caso, estaria associada à formação da vida e da natureza, em si. Favareto (2007, p. 40), em alusão à ideia, ressalta: “[...] em Aristóteles, esta gênese está ligada a própria especulação sobre a natureza do mundo. Em grego, natureza - physis deriva etimologicamente do verbo phиo, que significa crescer, se desenvolver." Natureza é, portanto, segundo o filósofo grego, “[...] a geração de coisas que se desenvolvem”, é “[...] a essência das coisas que têm, elas mesmas, um princípio de movimento," A ciência, em tais condições, poderia ser definida como a teoria da "[...] natureza das coisas e, pois, de seu desenvolvimento."

Engels (1976) aponta a importância das aptidões humanas para o trabalho, ao longo do desenvolvimento da espécie, sob a dependência dos recursos naturais. Mais do que outras espécies, o homem incorpora habilidade de manuseio e "certo" domínio sobre a quantidade, a variedade e a disponibilidade dos recursos naturais. Para Favareto (2007), o desenvolvimento da humanidade é bem anterior à conceituação científica do termo e às diversas tentativas de explicá-lo, quer no campo das ideias, quer no senso comum. Assevera que

[...] a evolução biológica do homem é resultado de um processo de longuíssima duração. E o primeiro grande salto realizado no intuito de tentar submeter sob seu domínio os desígnios de sua condição sobre a Terra é algo que data de dez a doze mil anos atrás, é nesta época que surge a agricultura, numa revolução de importância similar a Revolução Industriais, à medida que permitiu a organização dos crescentes numerosos assentamentos humanos, a realização de inúmeros processos técnicos [...]. (FAVARETO, 2007, p. 39).

A invenção da agricultura e a associação das técnicas a ela interligadas possibilitaram compreender o processo de mudanças nas relações homem - natureza como condição sine qua non, nos primórdios do desenvolvimento histórico-social. A agricultura não é somente o fato de cultivar a terra, no aspecto simbólico dos termos culto 
O desenvolvimento como pressuposto na "natureza humana": das abordagens didático-metodológicas sobre desenvolvimento à abordagem territorial do desenvolvimento rural

e cultura (BOSI, 1994), ou o trato do solo como recurso vital de onde se produz vida, mas é um conjunto sistêmico da fixação do homem no lugar, a construção de novas ferramentas e utensílios e o aprimoramento de sua capacidade inventiva de produzir, através do próprio trabalho. A espécie humana deixou de ser coletora e, por meio da evolução técnica e produtiva, teve como principal signo o surgimento da agricultura. Essa revolução nasce vinculada às primeiras noções de racionalização do trabalho e dos meios de produção, utilizados e aprimorados. Ela se desenvolve na ruptura entre o nomadismo e o sedentarismo, a substituição primária da força bruta pelas ferramentas e utensílios manuais e na apropriação dos recursos naturais (solo, água, floresta, minérios), sob um controle mais ou menos organizado; técnico (WEBER, 1974).

A racionalização da vida social e o controle dos meios de produção impulsionaram esse processo revolucionário, anterior às relações de troca e acúmulo de excedentes. Para Weber (1974), essa racionalização advém da ação humana, ao decidir coletivamente alcançar determinado fim; objetivo. Num primeiro momento, esse processo produtivo esteve ligado ao desenvolvimento de técnicas vinculadas à exploração dos recursos naturais. Depois, processou-se a passagem do modo primitivo para o controle do processo de produção, pelo trabalho. Assim, Favareto (2007, p. 179) afirma que "o momento atual” expressa, "[...] na verdade, a etapa mais recente de um longo processo de desencantamento e racionalização que tem início nos tempos mais remotos da vida em sociedade." No entanto, a racionalização centrada no acúmulo e na produção de mais valia foi primeiramente percebida pelos capitalistas nas estruturas rurais, devido à apropriação das terras e dos demais recursos naturais, como destaca Weber (1974). Nas economias capitalistas industriais dos séculos XVIII e XIX, a mão de obra servil e abundante no campo, sem controle do tempo e dependente da natureza, aos poucos se transformaria em força de trabalho urbana, explorada e com tempo controlado, dando origem às novas classes sociais, as quais configurariam o arcabouço do que se chamaria "sociedade moderna" (WEBER, 1974; MARX, 1982). Pode-se dizer que a racionalidade humana passa a ser entendida como racionalidade econômica, e o desenvolvimento, sinônimo de crescimento econômico. Na perspectiva de Becker (2002), “[...] o desenvolvimento humano reduziu-se ao desenvolvimento econômico, perdendo as demais dimensões da vida e da própria espécie.” (BECKER, 2002, p. 64). 
O desenvolvimento como pressuposto na "natureza humana": das abordagens didático-metodológicas sobre desenvolvimento à abordagem territorial do desenvolvimento rural

Conceitos sobre o desenvolvimento surgiram no aporte das economias capitalistas, no final do século XX. De um lado, o modelo clássico, que defendia o desenvolvimento atrelado ao crescimento econômico, e, do outro, a opção de um novo modelo, equitativo e sustentável, considerando-se, todavia, a possibilidade humana de agir em benefício da sociedade em várias dimensões, principalmente quanto às relações natureza e sociedade.

\section{Abordagens sobre conceitos de desenvolvimento: a gênese do desenvolvimento econômico na sociedade moderna}

A ideia de desenvolvimento, no capitalismo, trouxe outros conceitos ligados ao termo. Um dos mais utilizados na sociedade moderna é o do crescimento econômico. Após a Revolução Industrial e as transformações nas relações de trabalho e nas bases produtivas, o termo desenvolvimento passou a estar associado à inovação, à produtividade, ao acúmulo de capital e à disponibilidade de novos bens e serviços, para satisfação das sociedades modernas, urbanas e industriais.

Engels $(1876,1891)$ e Marx $(1984,1999)$ apresentam o processo de modificação social nas relações de trabalho e nas novas relações natureza e sociedade, compreendendo a primeira como espaço de dominação humana. De acordo com Marx (1999), o processo de acumulação capitalista estaria intrínseco na apropriação da natureza, pelo uso e loteamento do solo, a exploração para a agricultura e a extração mineral; das descobertas e apropriação dos recursos energéticos e demais matérias-primas. No contexto da sociedade moderna, a noção de desenvolvimento engloba um conjunto de significados variados, ou seja, evolução econômica e financeira, sociedades tecnificadas e criativas, populações logicamente mais ricas e com maior poder de produção, exploração ávida dos recursos naturais e crescimento material acelerado; economias fornecedoras e consumidoras de bens e serviços, extremamente lucrativas. Nessa ordem, Gonçalves afirma: "Desenvolvimento é o nome síntese da ideia de dominação da natureza. Afinal, ser desenvolvido é ser urbano, é ser industrializado, enfim, é ser tudo aquilo que nos afasta da natureza e que nos coloque diante dos constructos humanos, como a cidade, como a indústria.” (PORTO-GONÇALVES, 2006, p. 62).

Clemente (2010), Favareto (2007, 2008), Furtado (1974), Gómez (2006) e Sachs (2000) destacam a "polissemia e banalização" desse conceito. Para eles, é necessário 
O desenvolvimento como pressuposto na "natureza humana": das abordagens didático-metodológicas sobre desenvolvimento à abordagem territorial do desenvolvimento rural

advertir que desenvolvimento, sob uma concepção ontológica, engloba uma multiplicidade de significados, constituindo-se numa polissemia de conceitos construídos ao longo da evolução do pensamento humano, através de abordagens metodológicas suficientes, nas várias áreas das ciências humanas.

$\mathrm{Na}$ sociedade moderna, desenvolvimento real e prático está relacionado ao pragmatismo ortodoxo da economia e do mercado financeiro, com novas conquistas no campo da ciência e da informação, dos ganhos estatísticos e do acúmulo e suas articulações aos elementos simbólicos a serem massificados e mercantilizados (BORDIEU, 2007; BAUMAN, 2010). Com a (re)afirmação do modo capitalista de produção, o conceito de desenvolvimento, nessa fase, estava propriamente ligado ao crescimento econômico, resumidamente, crescimento empresarial, melhoria do modo de vida urbano e ampliação da produção e da produtividade, nos setores da economia, como bem mostram Harvey (2004) e Abramovay (1999).

Em abordagem histórica dos ciclos do capitalismo, Schumpeter (1997) enfatiza que o sistema econômico não anda sempre para frente de modo contínuo, mas que ocorrem movimentos inversos e contrários ao "crescimento econômico". Esse desenvolvimento, na perspectiva capitalista, na verdade, é um recomeço e não a continuação do antigo. Acrescenta: a economia capitalista passa, de tempos em tempos, por crises estruturais, permitindo que haja uma reestruturação necessária para seu modelo de reprodução e exploração da força de trabalho, demonstrando como o modo de produção dominante se rearticula, através de um modelo contraditório, de construção destruição - (re)construção. Foi por volta de 1921 que o capitalismo inicia um grande ciclo de expansão. Esse modelo de desenvolvimento, essencialmente econômico, se balizou na existência de ciclos, nos quais há períodos de expansão e de crises. Confirma Schumpeter (1997) que o sistema econômico não anda sempre para frente, mas ocorrem movimentos contrários, contratempos e incidentes variados, que obstruem o caminho do desenvolvimento. Schumpeter (1997, p. 74) salienta que, no final século XX, o modelo desenvolvimentista ainda não era assim denominado; nesse sentido, prossegue:

[...] entenderemos por desenvolvimento, portanto, apenas as mudanças da vida econômica que não lhe forem impostas de fora, mas que surjam de dentro, por sua própria iniciativa [...] todo processo de desenvolvimento cria os prérequisitos para o seguinte. 
O desenvolvimento como pressuposto na "natureza humana": das abordagens didático-metodológicas sobre desenvolvimento à abordagem territorial do desenvolvimento rural

Solidificado esse processo nas bases produtivas dos setores das economias, revelou que existia uma necessidade sucessiva de renovação, de reorganização diferenciada, com agentes diferenciados, perante os padrões de vida global. Passa-se a levar em conta as dimensões de desigualdade e pobreza social, cada vez mais aviltantes, em relação ao status quo determinado pelas nações ricas.

Entretanto, mesmo se considerando o desenvolvimentismo como pressuposto do crescimento econômico, não se pode afirmar que um modo de produção tenha todos os componentes necessários para a expansão e a produção num mesmo tecido histórico e no mesmo espaço (MÉSZÁROS, 2002). No bojo do modelo desenvolvimentista, no final do século XX, surgem outras concepções sobre o desenvolvimento. O novo conceito teria como prerrogativa a alternativa que possibilitasse um novo modelo, além do sinônimo “crescimento econômico", que não passaria de mito, como comprovou Furtado (1974).

\section{O "Mito do Desenvolvimento Econômico"}

Ao significado de desenvolvimento se têm incorporado conceitos mais apurados, os quais apresentam linhas metodológicas atreladas ao materialismo histórico. Para Esteva (2006, p. 63), “[...] desenvolvimento tornou-se a categoria central na obra de Marx: foi revelado como um processo histórico que se desdobra com o mesmo caráter necessário das leis naturais," Além de ser entendido como crescimento econômico, constitui-se num “mito" (FURTADO, 1974) e ganha conotações ideológicas de controle social (GÓMEZ, 2006; SEN, 2010). Em 1947, na Carta das Nações Unidas, essa ideia fora focalizada em função do crescimento da renda per capita dos países pobres. Posteriormente, o discurso de Truman, em 1949, lançaria para o mundo a "era do desenvolvimento" (ESTEVA, 2006). Esse discurso, segundo Gómez (2006), inauguraria um novo paradigma para o desenvolvimento, o ideológico. Nesse campo, a construção da política de dominação norte-americana estaria ligada ao desenvolvimento das nações subdesenvolvidas debaixo da égide do mercado capitalista, num espectro relacionado ao continuum de crescimento econômico-desenvolvimento social. Tais seriam seus aspectos fundamentais: i) oposição ao comunismo; ii) fornecimento de matérias-primas baratas para a expansão industrial; iii) perigo do crescimento das populações pobres do Terceiro Mundo; e iv) geração de desequilíbrio mundial, em vista da oferta, principalmente de recursos energéticos e demais bens naturais essenciais para vida (GÓMEZ, 2006). 
O desenvolvimento como pressuposto na "natureza humana": das abordagens didático-metodológicas sobre desenvolvimento à abordagem territorial do desenvolvimento rural

Assim, em contradição ao desenvolvimento, foi criado um novo conceito para designar as economias pobres da época, o "subdesenvolvimento". Esteva, (2006, p. 66), argumenta que esse termo adquiriu conotação simbólica, uma vez que “[...] o subdesenvolvimento era a criação do desenvolvimento."

Para as economias pobres e primárias, o discurso do desenvolvimento econômico não poderia se resumir às teorias científicas e às políticas de crescimento econômico das grandes empresas multinacionais, as quais transferiam lucros às economias ricas, convertidas em transnacionais, exercendo forte monopólio nos mercados de matériasprimas naturais e no controle dos preços dos recursos naturais, em todas as áreas do planeta, influenciando suas estruturas produtivas, dependentes de recursos vitais para sobrevida das corporações e a vida das sociedades locais (FAVARETO, 2007).

A crença de que o progresso era algo natural e inerente ao ser humano, juntamente com a ideia de que só haveria desenvolvimento dentro do sistema capitalista e que o mercado habilitaria o uso dos recursos naturais, humanos e tecnológicos, trouxe aos países subdesenvolvidos a possibilidade de buscar o tão sonhado desenvolvimento, nos moldes capitalistas. Na América Latina, nasce a Comissão Econômica para América Latina e Caribe (CEPAL), com o propósito de elaborar planos econômicos para sustentar o desenvolvimento baseado na industrialização, mecanização do campo e aumento da demanda de produtos agrícolas (CANO, 2010, 2017; MELLO, 2006). Nessa região, nos anos 1970/80, inaugurou-se o "modelo desenvolvimentista" como suposta solução ao atraso das economias agrícolas e a industrialização tardia. Furtado (1974) apregoa que o desenvolvimento econômico, tal qual era disseminado pelas economias ocidentais, seria praticamente impossível de ser alcançado nas economias pobres, criticando a ideia de que os padrões de consumo dos países industrializados chegariam mais tarde a todos os países. A visão do desenvolvimento como "mito" e a busca de um modelo ideal trariam consequências, quase que irreparáveis, com reflexos no panorama social global atual.

Furtado (1974) estipula cinco aspectos fundamentais para o futuro crescimento econômico: i) a hipótese da existência de um colapso sobre a apropriação dos recursos naturais não-renováveis e a carência de recursos energéticos; ii) a poluição da atmosfera, das águas e dos solos; iii) o impacto sobre a diversidade cultural e social; iv) a possibilidade de levar os povos "da periferia" a se sujeitarem a enormes sacrifícios, a fim 
O desenvolvimento como pressuposto na "natureza humana": das abordagens didático-metodológicas sobre desenvolvimento à abordagem territorial do desenvolvimento rural

de legitimar o caráter predatório em nome do desenvolvimento; v) a justificativa da negação do Estado como solução para regulamentação das economias

Ele adverte que "o mito", na verdade, seria a imposição do modelo ocidental às economias pobres, nos moldes estabelecidos pelos países ricos, o que não seria viável numa perspectiva globalizada. Esse modelo exigiria muito esforço e sacrifício das sociedades pobres, e seu ritmo provocaria uma pressão sobre o meio físico. A ideia de mito surgiria como crítica ao crescimento econômico vinculado ao progresso industrial, imposto pela verticalização nos moldes neoliberais aplicados ao contexto do discurso democrático e das liberdades políticas, econômicas e sociais.

\section{A emergência do desenvolvimento social e o desenvolvimento humano}

A criação da ONU (1948) como mecanismo de segurança (econômica e política) para as economias desenvolvidas e de proteção contra as "políticas totalitárias" foi de fundamental importância para as novas frentes desenvolvimentistas. Os conceitos de desenvolvimento social, humano e sustentável ganharam conotações especiais, nos procedimentos metodológicos, ao se induzir a instituição de políticas públicas, projetos econômicos e sociais, e programas de desenvolvimento dirigidos aos países pobres. Nesse prisma, Arendt (1993) ressalta que as conquistas democráticas e a busca das liberdades políticas (individuais e coletivas) poderiam levar a um novo padrão da dignidade humana. Essa dignidade, num contexto de nação, suscitaria um processo de desenvolvimento homogêneo, social e humano, segundo enfatiza Sen (2010). Mesmo assim, a questão social foi primeiramente vista como utopia ou fruto de ideologias que visavam à redução das desigualdades. Entretanto, esses temas ganharam força e passaram a fazer parte das mesas de discussões internacionais, no espaço dos organismos internacionais.

Gómez (2006) entende que, nos moldes da globalização neoliberal do final do século XX, esse discurso apresenta duas estratégias: i) desenvolvimento como estratégia completa e complexa de legitimação do capitalismo, seja na sua fase keynesiana (19401970), seja na fase neoliberal (entre crises, 1970-1980), seja da globalização neoliberal, de paladino contra a pobreza (anos 1990); ii) desenvolvimento como estratégia, ao mesmo tempo, de reprodução do capital e de controle social, que, segundo o discurso oficial, serviria para consertar os transtornos temporais provocados pela dinâmica natural do 
O desenvolvimento como pressuposto na "natureza humana": das abordagens didático-metodológicas sobre desenvolvimento à abordagem territorial do desenvolvimento rural

sistema, permitindo que os pobres (subdesenvolvidos) possam desfrutar, num futuro muito próximo, das benesses que os ricos (desenvolvidos) já desfrutavam.

Desde então, o principal esforço em ir além do desenvolvimento econômico foi a criação do conceito de desenvolvimento humano, na ONU (SEN, 2010), referendado pelo Programa das Nações Unidas para o Desenvolvimento (PNUD). Conforme Sen (2010), o discurso sobre desenvolvimento ultrapassou o viés ideológico e alcançou dimensões sociais, na medida em que desperta capacidades humanas e qualidade de vida. Para ele, "[...] o desenvolvimento humano é, sobretudo, um aliado dos pobres, e não dos ricos e abastados." (SEN, 2010, p. 191).

Entrementes, as dimensões sociais e humanas do desenvolvimento não estão separadas das habilidades produtivas das pessoas, mas as influenciam na construção de uma proposta de desenvolvimento compartilhado; envolvem conquistas objetivas e subjetivas, materiais e simbólicas. Para além do crescimento econômico e do equilíbrio social, existem as necessidades básicas da cidadania, dignidade e liberdade. Os discursos sobre liberdade, qualidade de vida, possibilidade de emprego e acesso à ciência e tecnologia são, no final do século XX, a preocupação com a questão natural, da vida global e da ordem ecológica do planeta.

O primeiro Relatório do Desenvolvimento Humano, apresentado na ONU em 1990, resultou posteriormente na criação do Índice de Desenvolvimento Humano (IDH). Assim, os padrões para o desenvolvimento não seriam apenas os econômicos, mas abarcariam as esferas humana, espacial, territorial e ambiental. Em meio aos ideais de liberdade, o IDH se coloca como índice capaz de congregar renda e condições sociais de vida - acesso à educação, saúde, moradia e dignidade -, como pressupostos básicos, que seriam articulados, a partir da Rio-92. As estatísticas estipuladas para tal mensuração foram criteriosas e abrangeram áreas primordiais da vida social, com alta relevância em países pobres, sendo elas o índice de educação, a longevidade e o Produto Interno Bruto (PIB) per capita (ESTEVA, 2006; SEN, 2010). A construção do IDH foi capaz de sintetizar em escala numérica o desenvolvimento humano. O método adotado foi “[...] uma combinação de carência em termos de índices de expectativa de vida, de alfabetização de adultos e do PNB real per capita.” (ESTEVA, 2006, p. 73).

Antes do IDH, a ideia de desenvolvimento social ganhou importância política na Europa, porém, sempre ligada à dominação colonial, mesmo porque o crescimento 
econômico das sociedades estaria ligado ao colonialismo e ao controle das rotas comerciais e da exploração dos recursos naturais (MARX, 1982; MÉSZÁROS, 2002; HARVEY, 2004). O pressuposto determinista da era capitalista de que desenvolvimento ocorreria como resultado do colonialismo traria, doravante, estabilidade social, voltada para novas formas de produzir bens e serviços, destinados a todos. Na antítese, o desenvolvimento social agora passa a ser medido pelo desenvolvimento humano, construído de forma comunitária e social, dotado de políticas de proteção, controle e afirmação positiva.

Nesse contexto, Sen (2010) aponta o pressuposto da liberdade como impulso para o desenvolvimento, em diversos níveis de ação, seja nas sociedades avançadas, seja nas sociedades pobres. Na antítese ao liberalismo, seriam consideradas as ideias de liberdade de trabalho, informação, consumo, acesso à tecnologia e na escolha de lideranças. Na mesma linha, Veiga (2008) salienta que desenvolvimento tem a ver com acesso à alimentação, trabalho, assistência social, saúde, saneamento básico e participação na condução das políticas públicas; liberdade ao acesso a bens naturais - essenciais à vida comum. Já Sachs (2008, p. 14) afirma: “[...] o crescimento, mesmo que acelerado, não é sinônimo de desenvolvimento se ele não amplia o emprego, se não reduz a pobreza e se não atenua as desigualdades." Embora, no espaço e no tempo, as concepções sobre desenvolvimento sejam multifacetadas, a linha metodológica aqui proposta evidencia a metamorfose na construção dessas concepções, não somente econômicas e tecnológicas, mas no campo do pensamento político e social.

\section{O desenvolvimento sustentável e a questão ambiental no capitalismo atual}

Ao reconhecer o desenvolvimento humano como modelo de desenvolvimento amplo e equilibrado, Sen (2010) ressalta que desenvolvimento não pode ser um conceito reduzido e esvaziado, mas parte de um conjunto de princípios que culminam na promoção de liberdades que garantam segurança econômica. Destaca:

[...] as recompensas do desenvolvimento humano, como vimos, vão muito além da melhora direta da qualidade de vida, e incluem também sua influência sobre as habilidades produtivas das pessoas e, portanto, sobre o crescimento econômico em uma base amplamente compartilhada. (SEN, 2010, p. 191).

Com a emergência das abordagens sobre o desenvolvimento humano, o desenvolvimento será tomado como o marco na busca de um equilíbrio entre exploração 
equilibrada, proteção ecológica e manutenção dos recursos naturais na possibilidade de acesso dos materiais no planeta (ABRAMOVAY, 2013). Montebelier-Filho (2008) e Abramovay $(2009,2013)$ afirmam que o modelo de desenvolvimento atual tem seus paradigmas ligados à economia ambiental e, portanto, não se trata de um discurso inteiramente novo, todavia, adequado a um novo mito, o do "desenvolvimento sustentável". Conforme Sachs (2008), esse conceito abrange cinco pilares: o social, o ambiental, o cultural, o territorial e o econômico. Assevera que não há como promover desenvolvimento, mesmo nas economias industriais, sem se levar em conta, hoje, a questão do meio ambiente. Para ele, nos anos 1990, começa um "casamento conceitual" do meio ambiente com o desenvolvimento. Abramovay $(2009 ; 2013)$ enfatiza que a tendência entre a preservação ecológica e o "ecodesenvolvimento" deve ser entendida não somente no campo teórico das aulas de educação ambiental e no meio científico com pesquisas e inovações tecnológicas -, mas também nas esferas política, legislativa e econômica dos Estados modernos e das corporações empresariais.

As tendências de mudança no discurso começaram a ganhar força, porém, apenas em 1972, na Conferência de Estocolmo, sobre meio ambiente. Já a Comissão Brundland (1987) defendia que o desenvolvimento mais aceitável à contemporaneidade seria “[...] aquele capaz de preservar os recursos necessários às gerações vindouras.” (FAVARETO, 2007, p. 52). Segundo Veiga (2008, p. 187), “[...] a noção de desenvolvimento sustentável [...] procura vincular estreitamente a temática do crescimento econômico com a do meio ambiente." Ele afirma que o documento aprovado na comissão “[...] caracterizou o desenvolvimento sustentável como um conceito político e [...] amplo para o progresso econômico e social.” (2008, p. 113). Entrementes, Sachs (2000) argumenta que a “[...] natureza, quanto ela se torna objetivo de política e planejamento, transforma-se em meio ambiente [...]". E continua:

[...] raramente houve um conceito que representasse a natureza de uma maneira mais abstrata, passiva a vazia de qualidades do que meio ambiente [...]. Aplicar o rótulo meio ambiente ao mundo natural faz todas as qualidades concretas desvanecerem, mais ainda, faz a natureza parecer passiva e sem vida, simplesmente esperando sofrer ação externa. (SACHS, 2000, p. 127).

Portanto, não se separa “desenvolvimento sustentável” da questão ambiental, ou esses dois conceitos da perspectiva social humana, como lembram Porto-Gonçalves (2006), Favareto (2008), Montebelier-Filho (2008) e Abramovay (2013). Destarte, em nenhum momento da história, o capital esteve preocupado com os danos ambientais, 
O desenvolvimento como pressuposto na "natureza humana": das abordagens didático-metodológicas sobre desenvolvimento

contudo, levou sempre em conta o aumento da produção de mercadorias e da produtividade. Esse antagonismo se concretiza na medida em que existe, desde sempre, a tendência ao aumento dos custos dos bens agrícolas e de matérias-primas, como resposta à intervenção do capital sobre a natureza (MARX, 1982; MÉSZÁROS, 2010; BOFF, 2010).

No período atual, a consciência ambientalista precisa se difundir amplamente em benefício de todos os seres viventes do planeta, visando a promover dignidade das populações pobres. O discurso do desenvolvimento sustentável adquiriu conotações diversas em meio aos interesses dos capitalistas, como ocorreu nas políticas que almejam melhoria na qualidade de vida das populações pobres e das sociedades globais, em geral. O discurso ambientalista se tornou popular e corrente, nos meios científicos. MonbelierFilho (2008, p. 89) sustenta que "[...] o meio ambiente é, então, incorporado nas teorias existentes; teorias são elaboradas [...] especialmente tendo como referência o desenvolvimento sustentável.” Nessa linha, Rampazzo (2005, p. 182) salienta que “[...] esta nova percepção é fundamental para a busca de um novo padrão de desenvolvimento econômico apoiado numa melhor qualidade de vida para as gerações do hoje e do amanhã." Todavia, embora se busque hoje entender o conceito de desenvolvimento sustentável, junto é necessário compreender o desenvolvimento rural marcado pela modernização da agricultura, urbanização e, na esfera política, pela abordagem territorial de desenvolvimento.

\section{O desenvolvimento e a Abordagem Territorial do Desenvolvimento Rural}

Tento em vista, ao longo da história social, as abordagens conceituais sobre o desenvolvimento, observa-se que os fluxos de desenvolvimento econômico, social, humano e ambiental se confrontam diante das possibilidades de exploração dos recursos humanos e naturais do planeta. Esses fluxos seriam, segundo Piketty (2012), os grandes causadores das desigualdades sociais e econômicas e um futuro relativamente incerto e excludente para as populações pobres no mundo. Sabe-se, por conseguinte, que os modelos de crescimento econômico geram reflexos antagônicos e repercutem no âmbito dos territórios, ou seja, no poder do Estado e suas parcelas políticas e sociais. Desse modo, os espaços de construção das ações e do controle dos recursos colocam primeiramente o 
O desenvolvimento como pressuposto na "natureza humana": das abordagens didático-metodológicas sobre desenvolvimento

espaço rural como fonte desses principais recursos: terra (solo), água, minerais e vegetação.

Embora as teorias de desenvolvimento tenham origens nas sociedades industriais, o meio rural, mesmo sendo compreendido como negação do urbano, foi importante para o crescimento das economias desenvolvidas e, no início do século XXI, evidentemente representa imensas fatias dos ganhos de capital e de sustentação de economias mundiais (ABRAMOVAY, 2009). De acordo com Favareto (2007, p. 54), o desenvolvimento rural deixou de ser apenas uma "invenção" para "[...] dirigir as expectativas e os rumos das sociedades mais pobres", passando a ser um processo pelo qual se alcance a evolução social. Aos poucos, descartou-se a ideia de desenvolvimento rural como simples possibilidade de produção de bens de subsistência nas atividades agrícolas e trocas ou acúmulos de excedentes, como eram característicos, nos modos de produção précapitalistas (ABRAMOVAY, 1999).

Logo, o meio rural pode ser concebido hoje como parte substancialmente necessária para a (re)evolução das sociedades (FAVARETO, 2007). Doravante, cabe apresentar, de forma breve, as concepções econômicas para o rural, bem como a abordagem territorial do desenvolvimento rural, que está precisamente ligada aos conceitos de desenvolvimento discutidos neste texto.

\section{As concepções econômicas de desenvolvimento rural}

Após a Segunda Guerra, sofisticaram-se as bases do desenvolvimento econômico e o desafio passou a entender se o desenvolvimento poderia se expandir espacialmente, quer do urbano para o rural, quer das economias ricas em direção às pobres e vice-versa. Mas, antes desse período, no século XIX, a economia agrária já era observada como foco de desenvolvimento das nações europeias, visto que a expansão industrial levou ao campo, primeiramente, a mecanização, de maneira que a dispensa de mão de obra engrossou as fileiras de mão de obra urbana e o aumento populacional, forçando maior produção em quantidade de bens nas áreas rurais, como afirmava Kautsky (1986), à época. Nesse período, o meio rural era inserido na economia capitalista e se adaptava à nova conjuntura da propriedade privada, satisfazendo a necessidade de abastecimento alimentar das populações urbanas. Na verdade, a propriedade privada da terra atendeu em muito às necessidades da economia capitalista; em parte, como produção de mercadorias, 
em parte, como obtenção de renda pelo uso da terra. A respeito disso, Kautsky (1986, p. 23) salienta:

[...] o ponto de partida para a economia agrária foi a sede da propriedade agrícola, que passara a condição de propriedade privada. A essa propriedade pertenciam, além da residência e das construções anexas, uma faixa de terra cercada que se situava em torno dos prédios da sede.

Quando descreve os aspectos básicos da produção rural na Europa, no século XIX, Kautsky (1986) frisa que havia produções coletivas, como a agricultura e a criação de gado. Identifica que a propriedade agrícola passara a ser unidade de produção familiar, de sorte que, além da subsistência, se produzia excedente, comercializado nas aldeias e nas cidades, tanto para subsistência como para o mercado. Esse sistema empresarial agrícola nascia vinculado ao crescimento econômico capitalista e, não obstante, não só modificaria o meio de vida rural, mas o modus vivendi urbano. Acrescenta:

\begin{abstract}
A agricultura não constitui hoje em dia, por si mesma, nenhuma forma especial de ser existente na sociedade; seu desenvolvimento encontra-se ligado intimamente com o desenvolvimento social. Aquela iniciativa e força revolucionária que a agricultura não soubera produzir por si, a cidade incumbiu-se de fornecer. Assim, o desenvolvimento econômico da cidade passa a revolucionar as condições econômicas rurais, tornando necessárias, igualmente, uma revolução nas condições da existência da propriedade. (KAUTSKY, 1986, p. 33).
\end{abstract}

Nesse contexto, o crescimento econômico capitalista revolucionou os meios de produção e os contextos políticos e jurídicos relativos ao meio rural e à propriedade agrícola. As transformações não ocorreram simplesmente na estrutura agrária, na divisão espacial e social do trabalho e nos fins específicos da produção agropecuária, contudo, se incorporam a estas a modernização agrícola e a industrialização do campo, fatores que se sobressaem no conceito estruturalista de crescimento econômico, divergente daquilo que hoje tentamos entender como desenvolvimento integral (SEN, 2010) e, mais recentemente, como "ecodesenvolvimento" (ABRAMOVAY, 2013).

\title{
A Gênese do Desenvolvimento rural: a modernização agrícola e seus reflexos na economia capitalista
}

A gênese do desenvolvimento rural partiu das economias capitalistas da Europa. Ao setor agrícola incorporaram-se ciência, mecanização e meios de transportes. Marx (1982) enfatiza que os produtos agrícolas e demais matérias-primas produzidas no meio rural tomaram caráter mercantil, como produto resultante do trabalho humano. De fato, "[...] agricultura, outrora a mais conservadora de todas as atividades profissionais, e que 
O desenvolvimento como pressuposto na "natureza humana": das abordagens didático-metodológicas sobre desenvolvimento à abordagem territorial do desenvolvimento rural

durante centenas de anos não acusara nenhum progresso [...] tornou-se em poucos decênios a mais revolucionária de todas." (KAUTSKY, 1986, p. 53).

Na passagem do século XIX para o XX, a agricultura já apresentava aspectos que identificam isso: i) a propriedade privada da terra, estabelecida e; ii) a produção em larga escala, o mercado, a exportação. Mesmo assim, a evolução da agricultura não significaria um desenvolvimento social. A priori, algumas fragilidades ficaram expostas, quais sejam: i) a formação de espaços desiguais no campo; ii) o aumento da pobreza nas regiões com menor dotação de recursos naturais; iii) o acesso desigual aos recursos humanos e tecnológicos. As desigualdades, seja nos espaços rurais dos países pobres e ricos, seja nas economias primárias, aviltaram o surgimento de espaços extremamente desiguais, típicos do capitalismo (LOWI, 1995).

O desenvolvimento rural não se expressa como prerrogativa necessariamente bem articulada ao desenvolvimento agrícola. Cabe, nesse contexto, associá-lo a um conjunto de ações políticas, técnicas e econômicas, relacionadas a melhorias sociais e à qualidade de vida das pessoas. Em análise dos desenvolvimentos rural e agrícola, nota-se que o segundo está mais vinculado aos critérios econômicos e o primeiro, num âmbito históricodialético, mutatis mutandis, do conceito, reconstruído sequentemente, nas novas fases do capitalismo. Os estágios do desenvolvimento rural têm seus ápices e momentos históricos na passagem do trabalho servil para o assalariado e na mecanização da agricultura. A princípio, deu-se conta de que as economias estavam em largo crescimento, quer no meio rural, quer no urbano, entretanto, as regiões pobres continuaram ligadas à produção primária - muitas, num grau ainda primitivo.

A transferência do modelo europeu para os Estados Unidos da América (EUA) permitiu outro avanço no processo de desenvolvimento rural. As terras que pertenciam a um pequeno grupo aristocrático, ligado à Coroa inglesa, foram sendo incorporadas ao domínio público. Um sistema jurídico foi criado, a fim de desvincular os resquícios feudais da Europa, promovendo um "[...] sistema baseado na propriedade livre e alodial." (VEIGA, 2007, p. 68). Lá, a vitória dos liberais do Norte ante as opiniões conservadoras dos sulistas - sobre propriedade da terra e trabalho escravo - resultou numa reforma do sistema agrário e na expansão da agricultura para o interior do país. Nesse caso, na "aura ideológica liberal", foi o Estado quem tomou as rédeas para a conquista e o ordenamento 
O desenvolvimento como pressuposto na "natureza humana": das abordagens didático-metodológicas sobre desenvolvimento à abordagem territorial do desenvolvimento rural

territorial, principalmente no que se refere ao incentivo à ocupação, com base na apropriação das áreas rurais.

O cultivo de novas terras, mesmo em condições semiáridas do meio Oeste, condicionou as famílias de agricultores a desenvolver novos mecanismos de plantio e de criação. Isso impulsionou o desenvolvimento do meio agrícola e nos territórios recémocupados, ocorrendo paralelamente a modernização da agricultura e o desenvolvimento rural. Foram criadas condições para a legalização da propriedade da terra, implantados corredores de transporte e o financiamento estatal para bens de capital, máquinas e implementos, provocando grande deslocamento populacional rumo ao interior, entre 1800 e 1920. Já o dinamismo econômico dos EUA, no período entre guerras, ensejou o surgimento de empresas ligadas à fabricação de máquinas e implementos, insumos e sementes, e o desenvolvimento da pesquisa agronômica. Contudo, foi o aumento da demanda por alimentos, durante a Segunda Guerra, que intensificou a política de crédito rural e a produção de víveres. Após a guerra, quando se pensava na diminuição da demanda, ocorreu o contrário; aumentaram exponencialmente as exportações para o abastecimento alimentar dos países destruídos no conflito, retomando-se o aumento do consumo global (VEIGA, 2007). Com a economia em pleno crescimento, o desenvolvimento rural e o crescimento econômico ganham novas dimensões, quais sejam: a necessidade de um desenvolvimento social coligado à expansão industrial e do capital, juntamente às economias rurais desenvolvidas.

No caso das economias pobres, grande parte da população ainda residia no campo e dependia da agricultura rudimentar, para sobrevivência. Diferentemente do modelo fundiário norte-americano, a agricultura dos países pobres estava vinculada a uma estrutura fundiária concentrada, de baixa produtividade e reduzida inserção de mercado (HESPANHOL, 1997). Havia linhas divergentes que propunham o desenvolvimento rural: uma, abarcando a modernização dos meios de produção, da empresa agrícola e do agronegócio para exportação; outra, voltada para o desenvolvimento social, regional e territorial. Nos países pobres da América Latina, as políticas desenvolvimentistas visavam à modernização da agricultura como aporte para a indústria e reserva de mão de obra (FURTADO, 1974). Aproveitando as linhas estatais de financiamento, os agricultores empenhados na grande produção agrícola obtiveram lucro, a partir do momento em que se tornaram parte integrante do crescimento industrial. 
O desenvolvimento como pressuposto na "natureza humana": das abordagens didático-metodológicas sobre desenvolvimento à abordagem territorial do desenvolvimento rural

Por um lado, o crescimento das indústrias dos bens de produção, implementos agrícolas, inseticidas, produtos químicos e adubos criou vínculo entre modernização agrícola e setor industrial; por outro, o aumento da demanda por matérias-primas no mercado internacional alavancou a produção e o preço das commodities agrícolas (HESPANHOL, 2007). A introdução de um pacote tecnológico para a agricultura recebeu o nome de "Revolução Verde", marco referencial da modernização agrícola nos países subdesenvolvidos, como analisaram Martine e Garcia (1987). Hespanhol (2008, p. 119) destaca:

[...] para muitos países subdesenvolvidos, a adoção de um pacote tecnológico representava a possibilidade, por um lado, de alcançar rapidamente a autosuficiência alimentar e, por outro, de gerar a produção de um excedente agrícola negociável no mercado externo, repercutindo positivamente em todos os setores da economia.

Esse pacote tecnológico possibilitou o avanço das pesquisas e tecnologia no meio. Desde o momento em que os ecossistemas mundiais passam a ser controlados pelo capital industrial e financeiro, crescem também os questionamentos sobre os impactos negativos da "Revolução Verde". Todavia, os danos causados ao meio ambiente e à qualidade de vida, principalmente das populações pobres da Ásia, África e América Latina, não foram levados em conta. Foi na década de 1960 que os problemas ambientais emergiram nos EUA e na Europa e, nas décadas de 1970 e 1980, vão se tornando expressivos ao redor do mundo. Nesse horizonte, na década de 1960, “[...] os efeitos ambientais negativos gerados pelo crescimento econômico eram considerados externalidades negativas ao processo de expansão da economia." (HESPANHOL, 2007, p. 3).

Com a criação do Clube de Roma, em 1968, cientistas alertaram para o referido problema. No entanto, os prognósticos do estudo encomendado pela instituição foram fortemente criticados pelos representantes não apenas dos países desenvolvidos, como também dos países pobres. Com efeito, os impactos da "Revolução Verde", ocorrida no âmbito do setor agrícola, denotam a emergência de uma série de problemas ambientais. O discurso do "ambientalismo", que surge em escala global, passa a ser referenciado na escala local. Nesse contexto, o rural principiou, na década de 1990, a ser visto como o principal espaço de exploração racional dos recursos naturais e de preservação.

$\mathrm{Na}$ década de 1990, novas dimensões propiciaram a concepção de outra ruralidade, no âmbito dos países ricos da OCDE, na ONU e na Divisão de Desenvolvimento Rural das Nações Unidas para Agricultura e Alimentação (FAO), 
O desenvolvimento como pressuposto na "natureza humana": das abordagens didático-metodológicas sobre desenvolvimento à abordagem territorial do desenvolvimento rural

enquanto, nos países pobres e emergentes, pela instituição de políticas públicas para o meio rural que contemplassem populações e regiões menos favorecidas, conforme comentam Abramovay (2009), Cazzella, Bonnal e Maluf (2009). A abordagem sobre novos conceitos de desenvolvimento emerge, nos anos 1990, com fortes aspectos políticos. No meio acadêmico, pesquisas, análises e debates vão determinar a ótica do desenvolvimento sustentável, balizada num conjunto amplo de aspectos e elementos, os quais estão lotados nos territórios.

O desenvolvimento rural, contextualizado primeiramente como sinônimo de modernização agrícola e produção em larga escala, será analisado na perspectiva do território, considerando-se o poder econômico das populações rurais, as necessidades fundamentais do fornecimento de mão de obra, matérias-primas e da relação sociedade e natureza, presente no território.

\section{A emergência de uma abordagem territorial do desenvolvimento rural, 1990}

Doravante, é preciso compreender o território pela metodologia de conquista e ordenação dos recursos existentes e apropriá-los às classes sociais que exercem poder sobre ele. De acordo com Raffestin (1993), o controle territorial está ligado ao poder social, político e institucional. O território é instituído na ação de agentes que se apropriam do espaço concretamente, determinando sobre suas ações de controle, definições de limites e apropriação dos recursos naturais disponíveis. Ademais, Haesbaert (2010) afirma que uma das vertentes básicas é a "jurídico-política”, a qual se dá quando o espaço é delimitado e controlado, sob o exercício de um poder, geralmente estatal, não se restringindo à ação única desse agente. Nesse contexto, ações se manifestaram no exercício da territorialidade: i) o exercício do poder estatal na formulação de estrutura “jurídico-políticas”; ii) a apropriação de um espaço físico humanamente desconhecido por parte da construção social; e iii) os interesses eminentemente econômicos de grupos dominantes, ignorando-se fronteiras políticas.

Haesbaert (2010) argumenta que a territorialidade envolve um determinado controle sobre uma área ou espaço e pode ser entendida como estratégia a atingir, influenciar e exercer o controle sobre recursos e pessoas. Segundo ele,

[...] poderíamos dizer que o território, enquanto relação de dominação e apropriação sociedade-espaço desdobra-se ao longo de um continuum que vai da dominação político-econômica mais concreta e funcional à apropriação mais subjetiva e/ou cultural-simbólica. (HAESBAERT, 2010, p. 95). 
O desenvolvimento como pressuposto na "natureza humana": das abordagens didático-metodológicas sobre desenvolvimento à abordagem territorial do desenvolvimento rural

A execução dessas ações depende, de fato, de organização política e institucional. O desenvolvimento do território passa por um eixo entre políticas públicas e ação social. Assim, diferentes agentes podem ser estimulados na cooperação e no estabelecimento de estratégias locais e regionais.

Dematteis (2008, p. 39) assegura que "[...] não existe território perfeito para a dimensão do desenvolvimento local, porém existem territórios a serem interpretados [...]”. E acrescenta: “Os territórios não são rigidamente pré-determinados, mas são definidos durante o processo de construção do ator local, a partir de uma hipótese inicial de agregação territorial dos sujeitos participantes.” Para Cazzela, Bonnal e Maluf (2009, p. 40), três categorias de atores podem estar envolvidas: “[...] os atores políticos dos diferentes escalões de governo; atores privados ligados a empresas, bancos [...]; os componentes da sociedade civil, tais como associações culturais, esportivas, sindicatos e estruturas de educação."

\section{O entendimento do desenvolvimento rural a partir da perspectiva do território}

Considerando-se a importância da dimensão territorial do desenvolvimento, na OCDE, anos 1990, foi criada uma divisão de desenvolvimento territorial, de sorte a estipular novas concepções entre os limites do rural e do urbano, a FAO. Nela, o meio rural passa a ser definido por intermédio de sua relação com a cidade. Kageyama (2005) salienta que o Programa de Desenvolvimento Rural da OCDE (1996) definiu um conjunto de indicadores básicos para se entender desenvolvimento rural: população e migração; bem-estar social e equidade; estrutura e desempenho econômico; meio ambiente e sustentabilidade. Logo, esse conjunto contempla uma série de critérios estabelecidos para compreender o meio rural em toda sua amplitude definindo ruralidade pelo "conceito territorial e não-setorial" (ABRAMOVAY, 2009), mesmo porque, para ele, o território é mais do que um ambiente físico e um conjunto de relações entre empresas e indivíduos:

\footnotetext{
[...] possui um tecido social, uma organização complexa, feita por laços que vão muito além de seus atributos naturais, dos custos de transporte e comunicação. Um território uma trama de vínculos e raízes históricas, configurações políticas e identidades que desempenham um papel ainda pouco conhecido no próprio desenvolvimento econômico. (ABRAMOVAY, 2009, p. 47).
}

Conforme a instituição, haveria dois níveis hierárquicos: o nível local e o nível regional. Assim, rural e urbano seriam estudados como um continuum e não como 
O desenvolvimento como pressuposto na "natureza humana": das abordagens didático-metodológicas sobre desenvolvimento à abordagem territorial do desenvolvimento rural

negação do outro. O desenvolvimento rural levaria em conta essas escalas e os elementos nelas presentes, tais como redes urbanas bens distribuídas, recursos territoriais adequados e mercados com pluriatividade e dinâmicos (ABRAMOVAY, 2009). Todavia, essa proposta ganha força junto à formulação de políticas públicas direcionadas ao ordenamento territorial, decorrentes da existência de uma série de elementos, físicos e humanos, no território. De fato, Cazella, Bonnal e Maluf (2009, p. 39) enfatizam que “[...] o território não é, portanto, só uma realidade geográfica ou física, mas uma realidade humana, social, cultural e histórica." Nessa abordagem, a visão coletiva e institucional do território e a maximização - valorização dos recursos presentes - se sobressaem através da realidade humana, social, cultural e histórica. Nessa concepção, o território é produto comercializado e os diferentes atores sociais - políticos e privados - precisam articular ações, com o propósito de criar oferta de atributos territoriais.

Como exemplo, na Itália dos anos 1970, surgiu o programa "Terceira Itália", baseado na interação entre as proximidades dos distritos industriais e o caráter de industrialização difusa, na competitividade das empresas e seus processos de inovação, nas esferas acadêmicas e entre as redes de formuladores de políticas públicas (BRAGNASCO, 1996; SARACENO, 1994). Essa experiência demonstrou um grande número de pequenas e médias empresas, articuladas em rede com a forte base familiar de produção agrícola, com grau de urbanização que evitava a contradição entre rural e urbano. A partir dessa experiência, na OCDE, prevaleceu a importância do estudo da dimensão territorial do desenvolvimento, por intermédio de políticas públicas, que sinalizava para uma nova valorização do rural e da própria ruralidade. Segundo Abramovay (2009, p. 53),

[...] é em torno deste valor - e não somente de suas atividades econômicas setoriais - que se procuraram aqui as características mais gerais do meio rural: relação com a natureza, regiões não-densamente povoadas e inserção em dinâmicas urbanas.

Ao utilizar o termo capital territorial, Dematteis (2008) explicita o conceito de valor territorial agregado, através das ações coletivas em torno dos recursos imóveis, específicos e patrimoniais dos locais. Nesse caso, tais recursos são concebidos como meios que podem ser utilizados de forma democrática e coletiva, presentes no ambiente natural, do patrimônio histórico (natural ou humano), nos recursos de infraestrutura e nos bens incorporados no capital humano presente. Desse modo, entender o rural como 
O desenvolvimento como pressuposto na "natureza humana": das abordagens didático-metodológicas sobre desenvolvimento à abordagem territorial do desenvolvimento rural

território denota um conceito "polissêmico", porque se levam em conta vários enfoques quanto às políticas públicas e ações coletivas. Para tanto, a abordagem territorial do desenvolvimento rural está, entre outras vertentes, associada às políticas públicas, tanto quanto aplicadas ao meio rural, bem como contextualizadas para as regiões rurais pobres: quaisquer áreas miseráveis e excluídas do processo do desenvolvimento humano.

\section{Abordagem territorial do desenvolvimento rural: emergência de políticas públicas para o rural}

Embora o discurso usual se apegue atualmente à sustentabilidade, caminhos para o desenvolvimento integral têm sido trilhados, principalmente na promoção de políticas territoriais e ideológicas, nos Estados emergentes ou em vias de desenvolvimento. Quando se trata de sustentação das bases territoriais, isso não indica somente a conservação do conjunto dos recursos naturais, porém, realça o conjunto mais dinâmico das relações entre homem e natureza. O desenvolvimento desses espaços é, porém, um pressuposto para se entender a evolução de uma sociedade. Outrora observados como espaços antagônicos, de junção e dispersão - modernização e atraso -, os espaços urbano e rural denotam, na era da globalização, espaços com funções totalmente diferenciadas; são espaços interdependentes, relativamente não-separados, mas contíguos; de limites flexíveis, com relações de trabalho, econômicas e financeiras determinadas segundo os interesses de cada lugar (SANTOS; SILVEIRA, 2002).

Sob o novo discurso desenvolvimentista, vê-se a instituição de políticas associadas ao mundo rural, sobretudo nos países pobres e emergentes (SEN, 2010; FAVARETO, 2009; ABRAMOVAY, 2013). A nova visão sobre desenvolvimento rural para o século XXI se reflete na preservação da natureza e no combate à fome, nas políticas públicas e nos movimentos sociais. As economias mais atrasadas, além do crescimento econômico lento, não produziram um desenvolvimento rural com tecnologia, ocupação do solo equilibrada e adequada; possuem problemas com a distribuição de terras, de segurança alimentar e no exercício das políticas públicas para o setor. Abramovay (2013) reforça a ideia de que os países pobres devem olhar com maior atenção para as suas regiões rurais, porque as mesmas podem apresentar dinamismo, desde o momento em que se enxerga o rural não apenas como resíduo do urbano, mas como parte integrante de economias em ritmo de crescimento; “os obstáculos geográficos” - quais sejam, as 
distâncias, a dotação de recurso, infraestrutura, bens e serviços - podem ser ultrapassados. $\mathrm{O}$ autor tece as seguintes considerações sobre o desenvolvimento das regiões rurais:

Se o meio rural for apenas expressão, sempre minguada, do que vai restando das concentrações urbanas, ele se credencia, no máximo, a receber políticas sociais que compensem sua inevitável decadência e pobreza. Se, ao contrário, as regiões rurais tiverem a capacidade de preencher funções necessárias aos seus habitantes e também às cidades - mas que estas próprias não podem produzir - então a noção de desenvolvimento poderá ser aplicada ao meio rural. (ABRAMOVAY, 2009, p. 23).

Veiga (2007) e Favareto (2000) ressaltam que há uma série de aspectos, os quais devem ser observados com muita atenção, sobre o que se oferece para e pelo meio rural, no século XXI. Esses aspectos podem ser: i) enorme quantidade de pessoas residentes no campo - sobretudo nos países pobres; ii) algumas zonas rurais possuem riquezas autênticas e ímpares; iii) o desenvolvimento rural deve envolver todos os setores da sociedade; iv) as zonas rurais desempenham novas funções nas relações sociedade e natureza; v) as políticas agrícolas precisam se adaptar às realidades locais, na construção de um desenvolvimento sustentável, com a participação de agentes diversificados.

As políticas públicas implementadas pelas instituições internacionais e governos, nas regiões rurais, na década de 1990, deram a tônica sobre a efetiva abordagem territorial do desenvolvimento. Nesse aspecto, o mundo rural vem sendo observado como parte integrante do processo de desenvolvimento, não só porque é palco da produção de alimentos e outras matérias-primas, mas porque está intrinsecamente integrado à preservação, manutenção e uso equilibrado dos recursos naturais, os quais serão necessários para a qualidade de vida, seja no campo, seja na cidade. Outra questão é perceber o desenvolvimento rural como promoção do território, através da implementação de políticas públicas regionalizadas e locais, levando-se em conta todas as especificidades territoriais, porque muitas pessoas estão ligadas a esse setor, em várias partes do mundo.

Com efeito, o desenvolvimento territorial pode contemplar as ações de diversos atores, tendo-se em vista melhor aproveitamento dos recursos locais e os aspectos simbólicos presentes, transformando o conjunto diversificado em recursos socioeconômicos, no processo de construção do capital social, territorial. Nesse sentido, os "atores" locais se mobilizariam no sentido de aproveitar e difundir as "vantagens" do território, para haver a promoção do desenvolvimento. 
O desenvolvimento como pressuposto na "natureza humana": das abordagens didático-metodológicas sobre desenvolvimento à abordagem territorial do desenvolvimento rural

Estudos de Favareto (2007, 2009) e Veiga (2007) apontam para a viabilidade do desenvolvimento territorial rural, em função da agroecologia, da produção de alimentos, fibras e bioenergia e da sustentabilidade vista no prisma da totalidade, tanto dos recursos naturais, como do sistema de produção. Para Favareto (2007), isso significa a nova racionalização da vida rural no mundo, criando-se perspectivas de reprodução social na vida cotidiana. Essa racionalidade tem suas bases no plano material e na ascendência de interesses compatíveis com ações de conservação ambiental, seja pelas perdas geradas com o desgaste de recursos naturais que afetam tantas empresas, países e regiões, seja pela introdução de especialidades econômicas e intelectuais relativas a tais esforços ou ao aproveitamento dessas amenidades naturais como negócio ou como conforto material.

A importância do rural como parte integrante do processo de desenvolvimento ressoa na preocupação de se criar estratégias de sobrevivências e melhores condições de vida para famílias que possuem suas rendas ligadas, direta ou indiretamente, às produções agropecuárias ou outras atividades não-agrícolas, no campo e nas áreas urbanas, em pequenas cidades. No que concerne ao desenvolvimento territorial rural e especificamente aos efeitos da aplicação dessa nova abordagem de análise, Schneider (2003, p. 4) realça algumas "facetas": i) a melhoria do mercado em escala local e regional, por meio da aceleração das trocas comerciais e da competitividade; ii) o surgimento de iniciativas que venham a criticar o padrão técnico dominante; iii) as modificações no processo de produção, levando a maior flexibilidade e descentralização e a "[...] diluição das diferenças setoriais"; iv) modificação do papel do poder público e demais instituições que atuam em determinado espaço rural, abrindo alternativas para parcerias; e v) entender-se melhor a dimensão ambiental, a partir das ações locais, transformando os recursos ambientais em vantagens econômicas ou em investimentos, e não somente como como fonte de renda.

Nota-se que as políticas de ordenamento territorial têm visado principalmente dois focos de ação: o primeiro é a sobrevivência de muitas famílias que dependem do meio rural como fonte de renda, integral e parcial; o segundo é que o rural está intimamente voltado para a exploração dos recursos naturais; é nesse espaço onde se encontram os potenciais de exploração, de renda e da manutenção das condições de vida, no campo e nas cidades. Nesse aspecto, a importância do território na promoção do desenvolvimento 
tornou-se uma condição para intervenção no processo de indução de políticas públicas para o setor. Quanto ao emprego do território na promoção do desenvolvimento,

\section{[...] uma análise mais apurada [...] mostra que o enfoque territorial é permeável às noções de governança (interação e regulação entre atores, instituições e Estado) e de concertação social ou coordenação de interesses de autores que transcorrem em um espaço determinado que é o território. Tanto a governança como a participação passam a ser entendidas como de fundamental importância para determinar o novo papel das organizações e instituições locais. (SCHNEIDER; TARTARUGA, 2004, p. 109).}

Essa abordagem, que, a princípio, foi originária na Europa, atualmente está em foco, principalmente nos países de produção primária. Espera-se, por conseguinte, que o desenvolvimento territorial deva estar correlacionado à participação de atores conjuntos, passíveis à execução de políticas públicas, quando o território passa a ser visto e compreendido como unidade de referência e mediação das ações do Estado, valorizandose os atributos políticos e culturais das comunidades e dos atores sociais ali existentes.

No caso brasileiro, esse enfoque se tornou importante, a partir da década de 1990, com o surgimento de debates que envolviam estudos e reivindicações populares de grupos ligados às classes menos favorecidas, especialmente no meio rural. $\mathrm{O}$ enfoque foi dado pela implementação de políticas públicas que buscaram, num primeiro momento, atender à agricultura familiar, como também à conservação dos recursos naturais e seu manejo adequado, no meio rural. Nos primeiros anos do século XXI, esse debate ganha força junto ao governo Lula (2003-2010), na implementação das políticas sociais. Vários ministérios passaram a executar uma rede de políticas, como, por exemplo, o de Desenvolvimento Agrário (MDA), do Meio Ambiente (MMA), do Desenvolvimento Social e Combate à Fome e o Ministério de Integração Nacional. O PRONAF foi um dos primeiros exemplos dessas políticas aplicadas em todo o território nacional, desde a década de 1990.

Nos Estados, as secretarias estaduais do Meio Ambiente e da Agricultura e Abastecimento também adotaram políticas com ações que priorizam o manejo ambiental, a pequena propriedade e do desenvolvimento local, nos espaços mais marcados pelo histórico da exploração agrícola do solo, ao longo do século XX. Como exemplos disso, verificam-se os Programas Estaduais de Microbacias Hidrográficas e sua vinculação com o PRONAF, o Programa de Aquisição de Alimentos (PAA), ambos vinculados à produção familiar local em parceria com o poder púbico; o Luz Para Todos, no campo. Promoveram-se redes de ações junto aos mercados locais e regionais, objetivando o 
O desenvolvimento como pressuposto na "natureza humana": das abordagens didático-metodológicas sobre desenvolvimento à abordagem territorial do desenvolvimento rural

ordenamento territorial rural, contando também com os programas de assentamentos rurais encabeçados pelo Instituto Nacional de Colonização de Reforma Agrária (INCRA) e demais órgãos estaduais do setor. No processo de desenvolvimento rural, as ações locais de manejo, controle e gestão dos recursos naturais e o aprimoramento das relações com a natureza são vieses para o desenvolvimento rural equitativo e equilibrado, redução da pobreza e garantia de direitos básicos e inalienáveis à vida. Finalizando o item, vale citar Gómez (2006, p. 36):

[...] nos últimos anos, vem se afirmando uma outra visão sobre o meio rural, construída e difundida na escala global e que, no Brasil, vem conseguindo visibilidade sob os auspícios de políticos, técnicos e acadêmicos dedicados a propor opções para solucionar os impasses do meio rural: é o rural como lugar de oportunidades.

Porquanto, o meio rural contemporâneo surge como local de oportunidades que possibilitam o desenvolvimento social, territorial, sustentável, equilibrado e duradouro, no espaço urbano, nos mais amplos espaços mundiais, bem como nas regiões pobres que tentam se desvencilhar desse rótulo, em busca de novas identidades.

\section{Considerações finais}

$\mathrm{Na}$ formação do conceito de desenvolvimento, percebe-se a exigência de uma análise metodológica sobre a discussão teórico-conceitual do tema. O conceito de desenvolvimento sofreu várias interpretações, no decorrer das mudanças capitalistas do século XX, abrangendo, hoje, um significado ontológico, iminente e complexo, em relação às transformações econômicas, políticas e sociais presentes na sociedade globalizada em relação a seus paradigmas sobre promoção da vida e a inclusão de espaços pobres e alhures, no mundo atual. O crescimento econômico, por si só, não responde às novas prerrogativas de vida, promoção da paz, convivência coletiva, digna e solidária, dos povos. Ao conceito clássico foram incorporadas novas dimensões de análises, mais aceitáveis, como "desenvolvimento social" e "desenvolvimento humano" - como modelo de oferta e oportunidades às regiões pobres, e o "desenvolvimento sustentável" -, como necessidade para a promoção de sobrevida, melhor utilização dos recursos naturais, manutenção da vida e das próximas gerações do planeta.

A análise leva, todavia, a compreender que o modelo atual de "desenvolvimento sustentável" não pode ser pensado somente pela visão preservacionista; é necessário partir do pressuposto de que os espaços naturais sejam, hoje, componentes territoriais, e 
O desenvolvimento como pressuposto na "natureza humana": das abordagens didático-metodológicas sobre desenvolvimento à abordagem territorial do desenvolvimento rural

a essas territorialidades se acrescente o conjunto de elementos naturais e humanos presentes nos espaços, mais disponíveis no meio rural - de onde se busca compreender detalhadamente as economias primárias, sobretudo nas regiões pobres, carentes de melhores condições de vida e de acesso aos bens e serviços, visando ao convívio social mútuo, equilibrado e equitativo. Contextualizado, a abordagem territorial do desenvolvimento rural, contando evidentemente com a ação de agentes públicos e privados e do conjunto social, articulado numa rede de relações políticas, econômicas, humanas, espaciais e até simbólicas, pode significar um caminho menos sinuoso para a conquista do desenvolvimento integral, almejado pelas sociedades ao longo das últimas décadas.

\section{Referências}

ABRAMOVAY, Ricardo. Paradigmas do Capitalismo Agrário em Questão. 2. ed. São Paulo-Campinas: Editora da UNICAMP/Hucitec, 1998.

ABRAMOVAY, Ricardo. O futuro das regiões rurais. 2. ed. Porto Alegre: UFRGS, 2009.

ABRAMOVAY, Ricardo. Muito além da economia verde. 2. ed. São Paulo: Planeta Sustentável, 2013.

ARENDT, Hannah. A dignidade da política. Ensaios e conferências. 3. ed. Rio de Janeiro:Relume Dumará, 2002.

BAUMAN, Zigmunt. Capitalismo parasitário. Rio de Janeiro: Zahar, 2010.

BECKER, Dinizar F. (Org.). Desenvolvimento sustentável, necessidade e/ou possibilidade? 4. ed. Santa Cruz do Sul: EDUNISC, 2002.

BORDIEU, Pierre. A economia das trocas simbólicas. São Paulo: Perspectiva, 2001.

BOSI, Alfredo. Dialética da Colonização. São Paulo: Companhia da Letras, 1994.

BRAGNASCO, Arnaldo. Tre Italie. La problematica territoriale dello sviluppo italiano3. ed. Roma, Itália: Il Mulito, 1996.

CANO, Wilson. Celso Furtado e a questão regional no Brasil. Disponível em <http://www.redcelsofurtado.edu.mx/archivosPDF/cano2.pdf> Acesso em 10 jan. 2010 .

CANO, Wilson. Brasil: Construção e desconstrução do desenvolvimento. Campinas, IEA/Unicamp. Textos para discussão, 304. Jun. 2017. Disponível em 
O desenvolvimento como pressuposto na "natureza humana": das abordagens didático-metodológicas sobre desenvolvimento à abordagem territorial do desenvolvimento rural

http://www.eco.unicamp.br/docprod/downarq.php?id=3533\&tp=a. Acessado em 01 de julho de 2019.

CAZELlA, A. A.; BONNAL, P; MALUF, R. G. (Org.). Agricultura Familiar, multifuncionalidade e desenvolvimento territorial no Brasil. Rio de Janeiro: Mauad X, NEAD, IICA, 2009.

CLEMENTE, E. Cesar. O Programa de Microbacias Hidrográficas no contexto do Desenvolvimento Rural da Região de Jales - SP. 315f. 2010. Relatório de Exame Geral de Qualificação (Doutorado em Geografia) - Faculdade de Ciências e Tecnologia - FCT. Universidade Estadual Paulista - UNESP, Presidente Prudente, SP, 2010.

DARWIN, Charles. A Origem das Espécies, no meio da seleção natural ou a luta pela existência na natureza, 1 v., Tradução de Mesquita Paul. São Paulo: Martin Claret, 2003.

DEMATTEIS, Giuseppe. Sistema local territorial (Slot): um instrumento para representar, ler e transformar o território. Tradução de Marcos Saquet. In: ALVES, A.; CANDIOTTO, L.; CARRIJO, B. (Org.). Desenvolvimento territorial e Agroecologia. São Paulo: Expressão Popular, 2008. p. 33-46.

ENGELS, F. O Papel do Trabalho na Transformação do Macaco em Homem, 1876. Disponível em http://www.marxists.org/portugues/marx/1876/mes/macaco.htm. Acesso em: 30 de junho de 2019.

ESTEVA. Gustavo. Desenvolvimento. In: SACHS, Wolfgang. Dicionário do Desenvolvimento: guia para o conhecimento como poder. Petrópolis, Vozes, 2000. p.59-83.

FAVARETO, Arilson. Paradigmas do Desenvolvimento Rural em Questão. São Paulo: Iglu - FAPESP, 2007.

FAVARETO, Arilson. Retrato das Políticas Públicas de Desenvolvimento Territorial no Brasil. Documento de Trabalho ${ }^{\circ}{ }^{2} 26$. Dinâmicas Terriroriales Rurales.Santiago, Chile: RIMISP,, 2009.

FURTADO, Celso. O mito do desenvolvimento econômico. Rio de Janeiro: Paz e Terra, 1974.

GOMEZ, Jorge R. Montenegro. Desenvolvimento em (Des)Construção: narrativas escalares sobre o desenvolvimento territorial rural. 438f. 2006. Tese (Doutorado em Geografia) - Faculdade De Ciências e Tecnologia - FCT - Universidade Estadual Paulista, UNESP, Presidente Prudente, SP, 2006.

HAESBAERT, Rogério. O mito da desterritorialização: do fim dos territórios e multiterritorialidade. 5. ed Rio de Janeiro: Bertrand Brasil, 2010. 
O desenvolvimento como pressuposto na "natureza humana": das abordagens didático-metodológicas sobre desenvolvimento à abordagem territorial do desenvolvimento rural

HARVEY, David. A condição pós-moderna: uma pesquisa sobre as origens da mudança cultural. São Paulo: Loyola, 2004.

HESPANHOL, A. Nivaldo. Políticas Públicas, modernização e crise da agricultura brasileira. In: Faz Ciência, Francisco Beltrão - PR, v,1, n. 1, p. 38-49, 1997.

HESPANHOL, A. Nivaldo. O Desenvolvimento rural na França e no Brasil: experiências LEADER no Centro Oeste da Bretanha e do Programa de Microbacias Hidrográficas no Estado de São Paulo. In. CONGRESSO EUROPEU DE AMERICANISTAS - CEISAL, Bruxelas, 2007. p. 1-15. Disponível em: < http://www4.fct.unesp.br/nivaldo/Pos-Graduacao/Lato-GARCA/MICROBACIASLEADER-CEISAL.pdf. Acesso em: 30 de junho de 2019.

HESPANHOL, A. Nivaldo. Os Programas de Microbacias Hidrográficas no Brasil. In: MARAFON, Glaucio José; PESSOA, Vera Lucia Salazar (Org.). Agricultura, Desenvolvimento e Transformações Sócioespaciais: reflexões interinstitucionais e constituição de grupos de pesquisa no rural de no urbano. Uberlândia: Ed. UFU, 2008, p. 1-12.

HESPANHOL, Rosangela A. M. Agroecologia: limites e perspectivas. In: ALVES, Adilson F.; CARRIJO, Beatris R.; CANDIOTTO, Luciano Z. P. Desenvolvimento Territorial e Agroecologia. São Paulo: Expressão Popular, 2008. p. 117-136.

KAGEYAMA, A. Produtividade e Renda na Agricultura Familiar: efeitos do PRONAF - Crédito. Agric. São Paulo (SP), v, 50, n, 2, p. 1-13, 2003.

KAUTSKY, Karl. A questão agrária. Tradução de Otto. E. W. Maas. São Paulo: Nova Cultural, 1986 (Os Economistas).

LÖWY, Michel. A Teoria do desenvolvimento Desigual Combinado. Actuel Marx, Paris, n. 18, p. 73-79, 1995.

MARTINE, George; GARCIA, Ronaldo C. Os impactos sociais da modernização agrícola. São Paulo: Caetés, 1987.

MARX, Karl. A chamada acumulação primitiva. In: MARX, Karl. O capital. Rio de Janeiro: Zahar, 1982, p. 171-189.

MARX, Karl. Formações econômicas pré-capitalistas. In: PINSK, Jaime. Textos 2 Modos de produção na antiguidade. São Paulo: Global, 1984. p. 11-17.

MARX, Karl. Para Crítica da Economia Política: do capital; o rendimento e suas fontes. Tradução de Edgar Malagodi. São Paulo: Nova Cultural, 1999 (Os Pensadores).

MELLO, Pedro Carvalho. Uma visão comparativa do conceito de desenvolvimento econômico de furtado com as teorias recentes. História e Economia, revista interdisciplinar, São Paulo, v. 2, n. 1, 2º sem, p. 107-134, 2006. 
O desenvolvimento como pressuposto na "natureza humana": das abordagens didático-metodológicas sobre desenvolvimento à abordagem territorial do desenvolvimento rural

MÉSZÁROS, István. Para além do Capital. Tradução de Paulo C Castanheira e Sergio Lessa. Campinas-São Paulo Ed. da UNICAMP-Boitempo, 2002.

MONTEBELLER-FILHO, Gilberto. O mito do desenvolvimento sustentável: meio ambiente e custos sociais no moderno sistema produtor de mercadorias. 3; ed. Florianópolis: Editora UFSC, 2008.

PIKETTY, Thomaz. O capital no século XXI. Rio de Janeiro: Intrínseca, 2014. PORTO-GONÇALVES, Carlos W. A globalização da Natureza e a natureza da globalização. Rio de Janeiro: Civilização Brasileira, 2006.

RAFFESTIN, Claude. Por uma Geografia do Poder. Tradução de Maria Cecília França. São Paulo: Ática, 1993.

RAMPAZZO, Sonia Elisete. A questão ambiental no contexto do desenvolvimento econômico. In: BECKER, Dinizar F, (Org.). Desenvolvimento sustentável, necessidade e/ou possibilidade? 4. ed. Santa Cruz do Sul: EDUNISC, 2002. p. 161-190.

SACHS, Ignacy. Desenvolvimento, includente, sustentável, sustentado. Rio de Janeiro: Garamound, 2008.

SACHS, Wolfgang. Dicionário do Desenvolvimento: guia para o conhecimento como poder. Petrópolis: Vozes, 2000.

SANTOS, Milton. A natureza do espaço. São Paulo: EDUSP, 2002.

SARACENO, Elena. O conceito de ruralidade: problemas de definição em escala européia. Tradução de Angela Kageyama, 1996 (mimeo).

SILVEIRA, M. Laura; SANTOS, Milton. O Brasil: território e sociedade no início do século XXI. São Paulo: EDUSP, 2002.

SCHNEIDER, Sergio (Org.). A diversidade da agricultura familiar. Porto Alegre: UFRGS, 2006.

SCHNEIDER, S.; TARTARUGA, I. G. P. Território e Abordagem Territorial: Das referências cognitivas aos apostes aplicados à análise dos processos sociais rurais. Revista Raízes, v. 23, n. 01-02, p. 101-116, jan./dez. 2006.

SCHUMPETER, J. A. Teoria do Desenvolvimento Econômico. São Paulo: Nova Cultural, 1997.

SEN, Amartya. Desenvolvimento como liberdade. São Paulo: Companhia das Letras, 2010.

VEIGA, José Eli. O Desenvolvimento Agrícola; uma visão histórica. São Paulo, Edusp, 2007. 
O desenvolvimento como pressuposto na "natureza humana": das abordagens didático-metodológicas sobre desenvolvimento à abordagem territorial do desenvolvimento rural

VEIGA, Jose Eli. Desenvolvimento Sustentável: o desafio do século XXI. Rio de Janeiro: Garamound, 2008.

WEBER, Max. A objetividade nas Ciências Sociais. In: WEBER, Max. Col. Grandes Cientistas Sociais, São Paulo: Ática, 1974. 